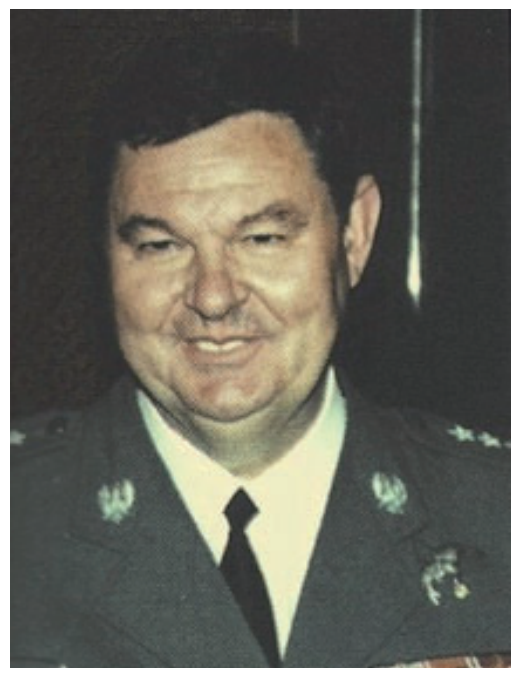

\title{
MILITARY INSTITUTE OF AVIATION MEDICINE IN WARSAW - DETECTIVES IN WHITE APRONS...
}

Jerzy GOTOWAŁA

Source of support: Own sources

Author's address: J. Gotowała, Kraski 24/3 Street, 02-804 Warsaw, Poland

Abstract: The author, a retired general and former Commander of the Polish Air Force, shares with the Reader the recollection of the Military Institute of Aviation Medicine in Warsaw from the perspective of a military pilot - a former customer and patient of this Institute. The author's introspections are presented in the form of an interesting literary essay.

Keywords: Polish Military Aviation, Military Institute of Aviation Medicine in Warsaw, medical and psychological examinations of military pilots

Figures: 2 • Full-text PDF: http://www.pjambp.com • Copyright @ 2017 Polish Aviation Medicine Society, ul. Krasińskiego 54/56, 01-755 Warsaw, license WIML • Indexation: Index Copernicus, Polish Ministry of Science and Higher Education 
While still studying piloting in Dęblin, captain Kuryłło - a feldsher who dealt with minor ailments of cadets (called by us a "healer") on almost every occasion reminded us of the duty to defend ourselves against what he called the "disease of indifference". More or less, it consisted in "... actively evaluating oneself and one's environment, breaking one's reprehensible behavior and appreciation of correct life. Since people in your profession must be able to think creatively, evaluate the situation and act quickly and precisely before anyone else. This in turn can be ensured by a correct, disciplined, and noble life. If you do not fall from the sky too early - he used to say with his bushy eyebrows raised upwards - you can live even a hundred years...". Of course, we underestimated the ramblings of the old feldsher ("not even a doctor"), but soon he was to turn out to be an experienced, wise man.

After promotion and first months in the fighting regiment I could call myself an absolute layperson in medical sciences. But as I gained my aviation experience, I became more and more interested in the humanistic aspect of our "pilot behaviors", and at that time I often thought back to the reflections of old man Kuryłło. A wider, more serious, more engaged interest arose in me in the years 1976-1982 from necessity, when I was entrusted with the command of the fighter regiment, and later with a position of the chief of the Corps and the Air Force and Air Defense. After several months of commanding the regiment, I had already known that the thorough knowledge of individual pilots combined with daily observation of behavior was conductive to reveal personal traits, an early form of pathology, which must be quickly and skillfully prevented. At that time, during the annual tests at Military Institute of Aviation Medicine (MIAM) ("talented, group I"), I spent more time on talking with specialists, sharing my observations and expecting advices, guidelines on what to pay attention to in order to timely prevent the causes of air accidents, failures and catastrophes. What symptoms may indicate that problems are coming?

No one underestimated my interests, I found a lot of conversations very interesting, and the observations, remarks and tips - as it turned out many times later - had been accurate and very helpful: $\mathrm{dr}$. R. Dąbrowa and dr. L. Kopka indicated the symptoms of risks connected with the functioning of the circulatory system, M. Wojtkowiak - the impact of overloading on the well-being of pilots, dr. K. Klukowski - spinal disorders, dr. J. Kubiczkowa - the impact of the frequency of high altitude flights on the body , dr. Z. Gierowski with dr. J. Domaszuk - the impact of exhaustion in aviation and the prophylaxis. Also dr. J. Hornowski, prof. S. Barański, prof. K. Kwarecki, dr. S. Milewski, dr. M. Chodorowski and dr. E. Marks added valuable remarks.

On the basis of wide information I had obtained that way, I adopted four basic principles in my work. I mainly paid attention to them in the case of instructor flights, organization of aviation training, exercises and ordinary everyday aviation routine.

The first postulate was to recognize and overcome fears. It is obvious that everyone, even "fearless airmen", are afraid of something. Loneliness and fear up in the air usually give rise to intrusive ideas about what can happen in a moment and definitely have a negative impact on well-being. And they are not rare among flying personnel at all, but they appear almost on a daily basis, almost constantly, always. But how to detect them in advance, how to free someone from overwhelming thoughts. Because they are often enough to cause anxiety, even fear. Meanwhile, young regimental general practitioners, as a rule, were not prepared to detect symptoms of "neurosis" in advance, symptoms occurring almost simultaneously: accelerated pulse, hypertension, light sweat, anxiety in the pre-flight examinations. But together with the squadron, flights commanders and instructors should notice it.

A pilot, who came to the conclusion that they cannot cope with some mistakes in the air, that they exceed their skills, usually avoids them, avoids situations in the air in which they can occur, after all setting traps for themselves which they sooner or later fall into. All the wisdom is to notice these conditions in time, to detect them. Because everything that is unknown is mysterious and usually arouses fear. But this fear slowly disappears when the stress situation is experienced in the presence of an accompanying person - preferably a colleague, a friend or an instructor. In turn, we used to consider familiar things as simple and ordinary, and the goal is to train such feelings. That is why the real difficulty was to detect the symptoms of anxiety in time and then to skilfully bring the pilot closer to the behavior of their older pilot-colleagues, instructors, for whom the availability of these skills was obvious. It was necessary to sensibly combine the "old and the young", the instructors and the students, in the air. And after a few casual training flights, the fear diminished noticeably until it finally disappeared.

The second postulate was associated with quite frequent cases of pain in the spinal region, almost always resulting from tension between the dorsal vertebrae, caused by overloads. They were usually intensified when young pilots advanced to the period of learning how to perform free piloting within 
the zone in the training process. On the day of the flight they have performed on their own one - two zones, and we, the instructors, four - five each (!). It was not easy to cope with it, because it is not easy to deal with reaching 5-6 G multiple times during one flight, and also there is the bundle of nerves, whether in the upper, back location of the loop, or during an Immellman's, when the speedometer indicates $450 \mathrm{~km} / \mathrm{h}$. The introduction of planes with variable wing geometry - "MiG-23" and then "MiG29 " - to the army resulted in a great increase of overload syndromes and injuries mainly to the cervical spine. These high loads (compression forces) are responsible for the creation of accelerated degenerative changes in the intervertebral discs. Military Institute of Aviation Medicine demanded the modernization of the centrifuge that had been in operation so far. Dr. M. Wojtkowiak and dr. J. Domaszuk had postulated modernization of the centrifuge since the $60 \mathrm{~s}-70 \mathrm{~s}$. We had found the money needed and in 1991 we already had a brand new centrifuge, with an IBM PC monitoring of the "flight". This also created opportunities to modernize old and develop completely new, better, more efficient Gsuits. Moreover: dr. M. Wojtkowiak, dr. J. Domaszuk and dr. K. Klukowski developed a series of relaxation exercises carried out on a hard, parquet floor with a medical ball under the knees and "rolling deep into oneself". Every two hours of physical education were started by the pilots by stretching the muscles of their feet, legs, abdomen and hands in the recommended position. Then the shoulders, neck and even face. Only after thirty minutes of such exercises they could move on to the muchloved team games. The pilots called it "taking off the bra" - but it helped.

The third health postulate was related to cases of alcohol abuse by pilots. Drinking itself is usually quite pleasant, but sobering is much worse - it usually brings about disappointment of some sort. In Poland, it has become a custom to blame other people, friends, colleagues and the most sophisticated circumstances for this. The reasons for air accidents in facilities are quite frequent, sometimes they involve failures, even disasters and ... they become a very important reason to drink. Meanwhile, as life has proved, it is not effective to instruct, even from the highest level of command, that no one can expect their own family and friends to understand this type of self-centered behavior and to understand making one's own impotence publicly visible.

Prof. S. Barański stressed very strongly the need to raise awareness, as often as possible, that it is a pity to ruin not only one's own body, but also the intellect in this way and, most importantly, to waste the prospects of long flying that every pilot has. This is what he considered to be the best recipe: "the best job is the one you like! The best recipe, as there is no pilot in our aviation who would not wish to fly and do anything but to fly, for as long as possible! And alcohol is, unfortunately, a temporary and poor assistant. And usually, sooner or later, it leads to deep addictions..." In extreme cases, aviation lost a few truly fantastic pilots every year. So it was necessary to instill in pilots the truth that it is beneficial to learn to live without it.

However, I considered depressive mood to be the most difficult problem to solve. Catapulting or catastrophe in the regiment is usually caused by doubts, despair, a sudden loss of energy, a noticeable weakening of will, sometimes a farreaching bitterness. Suddenly, doubts and the feeling of lack of perhaps a positive solution from a similar situation in the air manifest themselves or even start to dominate in a person. Usually several pilots get sick immediately, others are overwhelmed by apathy noticeable to the naked eye, they sleep poorly, and suffer from fatigue. Lack of enthusiasm and willingness to act becomes noticeable. Because suddenly we have to say goodbye to a person who everyone in the "local aviation family" knew very well, whom they were flying with, valued, and who is now irrecoverably... lost. Usually it took time, a lot of time, to come to terms with it - a time that nobody in the combat unit had. It was necessary to look for and find a rapid solution in order to forget, to learn to live without them. In such situations, there were cases of deep and serious with the family concerning the future. Every pilot had to decide when and whether to return to flying at all. And if so, if one choses to continue to fly, how to find confirmation of one's personal, professional and piloting value in everyday work.

These discussions, these valuable tips and recommendations from Military Institute of Aviation Medicine specialists were the basis for revising the current way of thinking, rejecting circulatory, routine, fixed views, conservative perception of the aviation profession and considering it from a completely different angle. It was science supported by medical experience. Today we can say, that when I took command of the Air Force, the science which, from today's point of view, has brought positive results, has changed the way of thinking and behavior of the commanders of the aviation regiments. Truly excellent psychological criteria for aviation training, prepared by the Department of Psychology, were adopted in the army 
with no reservations, in total, both at the school in Dęblin and by the instructors in the facilities. Since then, I have visited the office of dr. Z. Gierowski and prof. S. Barański every year familiarizing myself with a comprehensive analysis of the level of health of flying personnel, deficiencies, threats, directions of undertaken prophylaxis. I have put great emphasis on advanced prevention leading to the elimination of factors from the environment of flying personnel, which are exposed as harmful for well-being, health, fitness, atmosphere in facilities and intensive creation, promotion of conditions affecting the improvement of these factors. In secret, after such analyses, I have even once came to the conclusion that if the recommendations of this prophylaxis were carefully observed in the regiments - after all, anyone can dream perhaps in the following year we would be happy to congratulate ourselves on getting rid of a significant number of these "issues".

We have always given great respect to all physicians, especially to our specialists from MIAM. But then, for few months we had been admiring "people in white", miracle makers from Zabrze, although the heart transplants of prof. Bernard had been applied in world medicine for three years then. They were slowly becoming a standard in the world, and it was a complete novelty in our country. After all, the moral dilemmas in the Polish parliament and in the media were widely recognized as resolved and in the first operations undertaken in the country it was discovered that what really matters was finding a donor that would meet the needs and ... time. That goddamn time, which always slips through our fingers too quickly.

When, due to simple human curiosity, I became interested in this problem, prof. K. Kwarecki in his office at MIAM made me aware that this extraordinary creature - a human heart taken out of the donor's body to give new life, must be transplanted within about three hours. Only three hours... Therefore it is necessary to make transplantations from donors who got caught by the unfortunate fate near the transplantation centers, i.e. Zabrze or Cracow. Moreover, in the clinic there was a needy recipient, who had been praying for a long time for an organ with appropriate parameters. And that is why there is such a small, even minimal number of operations performed in Poland. I came back to the command at Żwirki i Wigury street from Kwarecki with his words sounding in my ears, about how much our medicine loses, how much society loses, how much Poles lose. Because cases of clinical deaths were frequent in the entire country. The number of tragic accidents, including mainly road accidents, did not decrease at all, and was even increasing from year to year. And even the fastest car with emergency lights and signals, in a country without motorways and expressways, was not able to meet the challenge of "three hours". The only real means of transport in our conditions in this situation was an airplane and a helicopter. Although there was a medical aviation operating in the country, it was too slow and it had completely no possibility to transport the rescue team... with a sanitary service on board. These requirements were met only by a large transport airplane. The one that could be landed by its crew on both military and civil airports. A military one, of course, to avoid the communication bureaucracy that devours precious time and reduces the chance of the recipient receiving the transplant.

With the means of fast transport at its disposal, the Air Force Command suggested cooperation with the Cardiosurgery Clinic in Zabrze (prof. Zbigniew Religa), Cracow (prof. Antoni Dziatkowiak), the Medical Academy of Gdańsk (prof. Zdzisław Wojda) and the Children's Health Center in Warsaw (prof. Stanisław Januszewski). Since then, air transport crews, regardless of the prevailing weather conditions and time of day, Sundays or holidays offered help, carrying a sanitary car, medical crew and human organs. On Saturday, January 21, 1990, in the middle of the carnival night, the crew of It. col. Stanisław Florek from the 13th platoon broke through an extensive snow storm, overcame atmospheric icing and luckily reached Goleniów near Szczecin, and then returned to Zabrze with such a valuable heart. In the morning there was a telegram on the desk "The patient received a new heart, surgery was successful. On behalf of the medical team and the convalescent thank you...thank you...Thank you great Polish pilots! Religa....". Two months later, prof. Religa held a meeting with pilots during the annual Conference of the Armed Forces Flight Security. At the end of the lecture "The sense of illness, the sense of death, the sense of life. At the beginning of tomorrow's medicine" he helped us extremely in our health prophylaxis by stating without hesitation "...especially you, the pilots, you have to follow the life model so that no diseases can reach you - fight for a life without diseases...". The theses of his speech were confirmed by the Head of Health Service of the Polish Army gen. Kaliwoszka, the Head of WIML col. prof. Stanisław Barański and his deputy col. prof. Krzysztof Kwarecki.

On Thursday, April 5, 1991, Military Institute of Aviation Medicine - located at Krasińskiego street - was visited by the Prime Minister of the Re- 


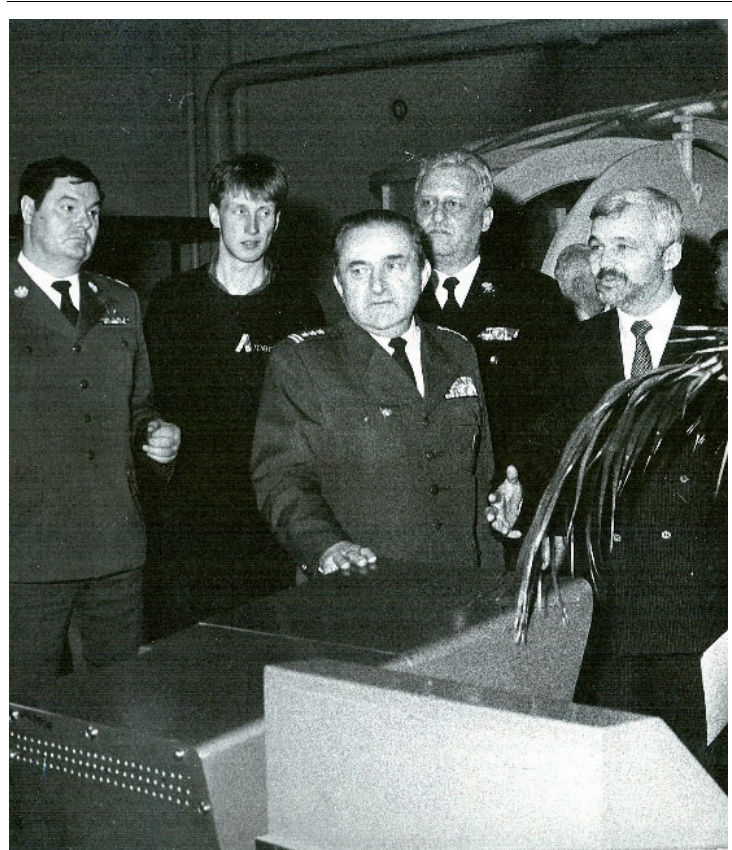

Fig, 1. Visit of the Prime Minister Krzysztof Bielecki at WIML in 1991 (on the left - Air Force Commander Gen. Jerzy Gotowała, inside -col. prof. dr hab. med. Stanisław Barański, on the right - Mr. Premier).

public of Poland - Jan Krzysztof Bielecki. He came in the company of adm. Piotr Kołodziejczyk from the Ministry of National Defense and the Head of Health Care of the Polish Army.

Together with the commander prof. S. Barański we have presented our institution. He became acquainted with the Institute's specialties: low pressure chamber, microwave laboratory, physiological test, centrifuge. He looked at the hospital's treatment base, which included 200 beds, and then we took him to the room of the working flight simulator "JAPETUS".

At the moment, the physical and mental condition of the pilot (Captain Strigl) was being examined and hydraulic actuators, on which the pilot cabin was supported, made a loud noise when changing its position depending on the stage of the "flight". Bielecki halted dead right after entering the room. "- Damn it! Where is Spilberg? Are you shooting the second part of Star Wars?" Prof. Barański explained the computer system supporting aviation and medical research, combined with the analysis of purely psychological indicators, enriched with information on the speed and quality of response of the tested pilot. The simulator made it possible to obtain reliable information about the pilot's state of health and even to answer the following questions: how does the pilot of a modern combat plane behave in conditions of acceleration? Do they make mistakes and how many do they make? Are they likely to put the safety of flights in danger? Will they accomplish their tasks accurately and effectively while operating on the modern battlefield? Holding in his hand the tape recording of the physiological parameters of the tested pilot from the medical computer network, it suggested the objectivity of evaluating the performance of the task set for the pilot. - This is the basis for conclusions regarding the physiological condition of the tested pilot drawn under the supervision of specialists: instructor-pilot, psychologist, engineer and doctor. - "That's good..." - said prof. Barański, glancing on the wide printout tape, but he was most interested in the "JAPETUSA" flight simulator cabin, which was "walking on hydraulic feet".

Then we took him to the Institute's internal courtyard, presenting him the buildings in the rooms of which the computer tomography and magnetic resonance will be located in the future. Just at the moment when Jerzy Wojnar flew in from PZL-Okęcie in an "Orlik", low from the side of Powązki. - This is our new trainer plane - I informed the Prime Minister. The pilot put the plane in a dogleg, presenting the beautiful silhouette of the machine and immediately moved to the vertical position. At an ascending angle of eighty

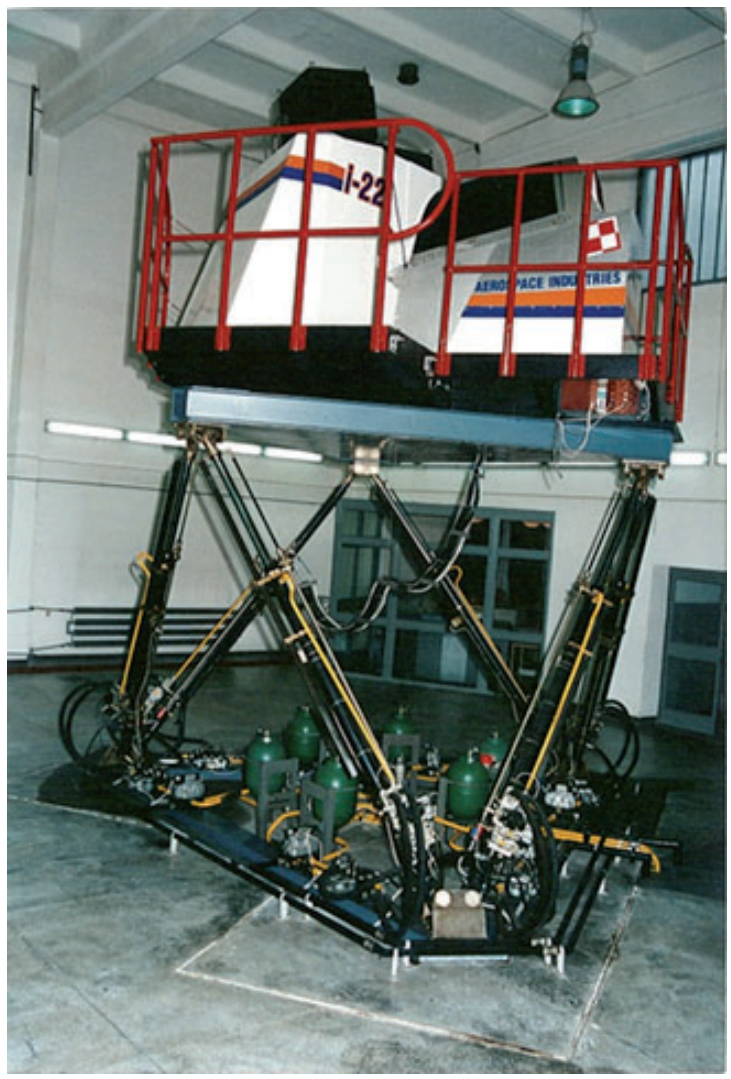

Fig. 2. Simulator "JAPETUS". 
degrees he turned the "Orlik" in the other direction and over our heads he performed one loop after another. At the end of the fourth one he descended low and again from Powązki he moved upwards in an aileron roll.

- "Are you satisfied with this machine?" - he asked with concern. - "Very much" - I have replied truthfully. - It is a plane for primary training, expected by the officer cadets of the "School of Eaglets" in Dęblin. The British and Israeli pilots already feel jealous about it... - "Oh! Is it our export product?" - this time he turned to the director of PZL - Okęcie, Ryszard Leja.

- "That is what we are hoping for, Prime Minister. We have inquiries from countries in South America, Israel and even China...". He seemed to be impressed by the operation of the Institute. However, it soon turned out that despite assurances, he did not allocate any significant amounts to MIAM - "Miser..." - as Barański called the donor.

Usually at the end of October, prof. Barański used to invite people to WIML "for coffee" to present the health condition of the flying staff of the Air Force and Air Defense and to present the noticed threats, resulting from the comprehensive analysis of the research results. "The scale of morbidity among pilots" - he usually started optimistically - "has remained at the same, good level so far, and I dare say that this is the result of the medicine praeventiva" practiced by MIAM's medical staff in health prophylaxis units. Also our annual meetings. But the source of this generally not bad situation are not only doctors, proper operation of our health centers, MIAM or care for good supply of medicines for pharmacies near aviation facilities, but also the growing level of knowledge, education, and susceptibility of pilots for the rules of health prophylaxis instilled in them. Aviation commanders and pilots must not only know them well, understand them, but simply take them as a standard, as a habit like everyday tooth brushing, like morning gymnastics.

Despite the selection applied every year during the periodic examinations, several pilots are disqualified for health reasons. This year, nine of them... The Commission considers the negative impact of working conditions, both in quantitative and qualitative terms, as a major cause as usual. This is the result of completing training in each regiment of young pilots and the still low level of prevention methods and measures...". After such a general introduction, the Professor moved on to traditional issues: overweight, neuroses and neurogenic diseases such as coronary heart disease, heart arrhythmia and hypertension, spinal injuries and complaints of pilots from medical his- tory. Specified in percentages, they painted a true picture of healthfulness. "Spinal disorders are mainly influenced by overloads and ordinary "wear and tear" processes, which can be permanently observed in a pilot at around the age of 40 . This is the beginning of the future "inability" of instructors in particular. All these elderly people will soon be included in the third disability group...." Then he moved on to the personnel. "The management of Air Force and Air Defense Aviation - bad, requires an immediate refreshment. The management of 1 Air Defense Division of the Country (ADDC) - "facing extinction": Robak, Radoń, Bogusz conditional permission to fly on a reduced scale. However, this may result in reasons of accidents". "The management of 2ADDC - similar situation. Pasiewicz, Bil, Sygnowski..." - names that I knew very well were mentioned, sometimes even of my former commanders and instructors. It was not easy to take it uncritically. "The management of 3 ADDC - the situation is slightly better, but it also needs to be improved: Pawłowicz, Stolarski, Jaszek - also reduced activity, reduced overload during flights". "The management of 4 Corps' Aviation" - after last year's human resources refreshment, the situation is good. There are labor shortages, needing to be supplemented.

The health situation of pilots in battle regiments was usually good. There were individual cases of reservations, but here the supplementations from the school in Dęblin resulted in prof. Barański devoting more attention to the atmosphere in the facilities, to the premises for air accidents and preventive recommendations. For me, it was extremely important to evaluate the prophylaxis applied, the abilities of facility commanders to create an atmosphere of trust and support in the process of cultivation in the air, the care for young pilots and the mitigation of the pilotage overload of instructors. The Professor emphasized the results of developed "pre-pathology" - early detection and applied prophylaxis, prevention of disease.

This discussion, these recommendations and comments became the basis for the summary of the training year and the tasks for the next one. But I have discussed this more firmly and clearly with the Chiefs of Corps' Aviation and the regiment commanders. Whether this prevented us from accidents and catastrophes - it is difficult to estimate, it is difficult to define unequivocally, although certainly YES! Even the maximum saturation of flight crew with doctors will not improve the health of the flying personnel significantly, unless the level of compliance with prevention rec- 
ommendations is appreciated, constantly raised and enriched by both biological and ethical values of the therapists, commanders, as well as the pilots. As prophylaxis equals shortcomings noticed in time and timely elimination of factors harmful to health and well-being from pilots' surroundings, as well as the persistent creation of conditions that support health. This is why the pilots left WIML after the annual examinations satisfied not only with the favorable verdict "capable, group I", but also with the colorful brochures on the preven- tion of basic diseases. Brochures containing information on how to live in order not to get ill, commented on and recommended by our doctors. It was precisely the detection of symptoms of flight safety hazards and the suggestion of preventive health measures that made me think of the detective search for hidden threats to the health of pilots, which were supposed to bring about and indeed brought about beneficial effects for aviation in terms of flying safety. MIAM personnel truly are detectives in white aprons...

\section{AUTHORS' DECLARATION:}

Study Design: Jerzy Gotowała; Data Collection: Jerzy Gotowała; Manuscript Preparation: Jerzy Gotowała. The Author declares that there is no conflict of interest.

Cite this article as: Gotowała J. Military Institute of Aviation Medicine in Warsaw - Detectives in White Aprons.... Pol J Aviat Med Bioeng Psychol 2017; 23(3-4): 7-13. DOI: 10.13174/pjambp.20.12.2018.02 